\title{
Ativismo judicial? o "antes" e o "depois" da constituição de 1988 na jurisprudência do Supremo Tribunal Federal: um estudo a partir da noção de vinculação dos particulares aos direitos fundamentais *
}

\author{
Judicial activism? the "before" and the after the \\ federal constitution of 1988 in the Federal Supreme \\ Court jurisprudence: an analysis of the binding of \\ fundamental rights in private law
}

\author{
Tássia Aparecida Gervasoni ${ }^{* *}$ \\ Mônia Clarissa Hennig Leal ${ }^{* * *}$
}

* Este artigo é resultante das atividades do Centro Integrado de Estudos e Pesquisas em Políticas Públicas (CIEPPP), financiado pelo FINEP e vinculado ao Programa de Pós-Graduação em Direito - Mestrado e Doutorado da Universidade de Santa Cruz do Sul (UNISC), em que as autoras desenvolvem o projeto de pesquisa "Controle jurisdicional de políticas públicas: análise da atuação do Supremo Tribunal Federal no controle de políticas públicas e a relevância da atuação do amicus curiae como instrumento de legitimação dessas decisões no Brasil", na condição de coordenadora e participante. $\mathrm{O}$ artigo se insere, também, no âmbito do projeto "O amicus curiae como instrumento de realização de uma jurisdição constitucional aberta: análise comparativa entre os sistemas brasileiro, alemão e norte-americano e sua efetividade na jurisprudência do Supremo Tribunal Federal", que conta com recursos do Edital das Ciências Sociais/2010 do CNPq e do Programa Pesquisador Gaúcho 2010, da FAPERGS.

** Doutoranda em Direito pela Universidade do Vale do Rio dos Sinos (UNISINOS). Mestre e graduada em Direito pela Universidade de Santa Cruz do Sul (UNISC). Professora de Direito Constitucional na Faculdade de Direito de Santa Maria (FADISMA). Professora na Universidade da Região da Campanha (URCAMP). Advogada. E-mail: tassiaag@yahoo.com.br

*** Pós-doutora em Direito pela Ruprecht-Karls Universität Heidelberg, na Alemanha. Doutora em Direito pela Universidade do Vale do Rio dos Sinos (UNISINOS), com pesquisa realizada junto à Ruprecht-Karls Universität Heidelberg, na Alemanha. Professora do Programa de PósGraduação em Direito - Mestrado e Doutorado da Universidade de Santa Cruz do Sul (UNISC), onde leciona as disciplinas de Jurisdição Constitucional e Controle Jurisdicional de Políticas Públicas. Coordenadora do Grupo de Pesquisa "Jurisdição constitucional aberta", vinculado ao CNPq. Bolsista de produtividade em pesquisa do CNPq. Coordenadora adjunta do Programa de Pós-Graduação em Direito - Mestrado e Doutorado da Universidade de Santa Cruz do Sul (UNISC). E-mail: moniah@unisc.br 


\section{Resumo}

Diversos fatores vêm conformando o Estado Democrático de Direito ao longo do tempo, como o fortalecimento da noção de direitos fundamentais e o reconhecimento da supremacia da Constituição. Fenômenos como a constitucionalização operam rupturas paradigmáticas na compreensão do próprio Direito, que reclama o desenvolvimento de mecanismos capazes de dar conta dos conflitos que se estabelecem nessa nova realidade. Tais mutações repercutem nas relações entre os indivíduos, que, ao se tornarem agentes de grande poder, não podem ficar imunes aos instrumentos de controle antes destinados apenas aos entes estatais. Para se adaptar a esse quadro, surgem teorias em defesa da vinculação dos particulares aos direitos fundamentais, tornando-se essencial a sua compreensão, bem como do modo pelo qual essas construções são consideradas pela Corte Constitucional. Com efeito, o presente trabalho objetiva investigar a evolução dos direitos fundamentais no Estado Constitucional e sua incidência nas relações entre particulares - notadamente com enfoque no chamado fenômeno constitucionalizador -, para, a partir disso, analisar a posição e a atuação da jurisdição constitucional brasileira relativamente a esses aspectos, traçando em torno da noção de ativismo judicial o "antes" e o "depois" da Constituição de 1988 na jurisprudência do Supremo Tribunal Federal. Apesar de alguma oscilação e de certa demora no enfrentamento do tema, hoje, é possível apontar claramente a posição da jurisdição constitucional brasileira não só quanto à defesa da vinculação dos particulares aos direitos fundamentais, mas também no que diz respeito à utilização da teoria da eficácia direta para tanto, conforme se pretende demonstrar.

Palavras-chave: Constituição Federal de 1988. Direitos fundamentais. Relações privadas. Jurisdição constitucional. Ativismo judicial.

\section{Abstract}

Several factors have been shaping the democratic rule of law over time, such as strengthening the notion of fundamental rights and recognition of the supremacy of the Constitution. Phenomena such as the constitutionalisation operate paradigmatic ruptures in understanding the law itself, which calls for the development of mechanisms to cope with the conflicts established in this new reality. Such mutations have repercussions on relations between individuals, who become the agents of great power can not remain immune to the instruments of control before intended only to state entities. To adapt to this situation arise in defense of theories linking the fundamental rights of individuals, making it essential for your understanding as well as the manner 
in which these buildings are considered by the Constitutional Court. Indeed, this study aims to investigate the evolution of fundamental rights in the State Constitution and its impact on relations between individuals (especially focusing on the phenomenon called constitucionalizador), for, as appropriate, analyze the position and the performance of Brazilian constitutional jurisdiction in respect of these aspects, drawing on the notion of judicial activism, the "before" and "after" the 1988 Constitution in the jurisprudence of the Supreme Court. Despite some oscillation and some delay in coping theme right, today is possible to point out clearly the position of the brazilian courts not only as to the defense of binding fundamental rights of individuals, but also with regard to the use of the theory of effective directly to both, as intended to demonstrate.

Keywords: Federal Constitution of 1988. Fundamental rights. Private relations. Constitutional jurisdiction. Judicial activism.

\section{Introdução}

Diversos fatores vêm conformando o Estado Democrático de Direito ao longo do tempo, dentre os quais figuram, certamente, o fortalecimento da noção de direitos fundamentais e o reconhecimento da supremacia da Constituição. Esses elementos se entrelaçam, desenhando novas perspectivas e trazendo inéditos desafios à jurisdição constitucional.

Fenômenos como a constitucionalização operam rupturas paradigmáticas na compreensão do próprio Direito, cujos operadores precisam se adaptar e desenvolver mecanismos capazes de dar conta dos conflitos que se estabelecem nessa realidade que se consolida.

As mutações do modelo de Estado e da sociedade como um todo, especialmente do que se considera esfera pública ou privada, repercutem nas relações entre os indivíduos. Um grande poder também surge nas mãos de entes privados, que não podem ficar imunes aos instrumentos de controle, antes destinados apenas aos entes estatais.

Como forma de contornar esse quadro, surgem teorias em defesa da vinculação dos particulares aos direitos fundamentais, tornandose essencial a sua compreensão, bem como do modo pelo qual essas 
construções são consideradas e aplicadas pelos Tribunais Constitucionais, especialmente no âmbito do Supremo Tribunal Federal, o que justifica o presente trabalho.

Pretendeu-se investigar, a partir dos referenciais teóricos vinculados a fenômenos como a constitucionalização do Direito e a dimensão objetiva dos direitos fundamentais, a evolução destes no Estado Constitucional e sua incidência nas relações entre particulares, para, a partir disso, analisar criticamente a posição do Supremo Tribunal Federal (STF) relativamente a esses aspectos, sobretudo após a Constituição de 1988, a fim de se verificar em que sentido a atuação do STF nessa seara pode ser classificada como "ativismo judicial".

\section{Os direitos fundamentais no Estado Constitucional e sua incidência (também) nas relações entre particulares: reflexos do fenômeno da constitucionalização do Direito}

É possível afirmar que o Estado Constitucional, até ser adjetivado de Democrático e de Direito devido à incorporação de diversas características inerentes a essas noções, evoluiu numa certa relação de causa e efeito com o desenvolvimento da sociedade e principalmente das ideias (fortalecidas) de Constituição e de direitos fundamentais (tudo isso determinando e sendo determinado pela atuação da jurisdição constitucional).

O atual modelo constitucional é resultado de uma série de transformações ocorridas no tempo. Para a presente abordagem, adota-se como marco histórico inicial o período liberal, berço do constitucionalismo. $\mathrm{Na}$ verdade, trata-se de uma narrativa da própria evolução do Estado, da sociedade e do Direito, já que uma multiplicidade de fatores converge para a formação dos entendimentos dominantes de cada época.

Do paradigma do Estado Liberal, destaca-se a separação entre Estado e sociedade - o surgimento da dicotomia público/privado -, cabendo àquele o papel de garantidor da liberdade individual. Os 
direitos fundamentais dizem respeito à esfera pública (regrada pela Constituição), como limites à ação estatal, pois, no âmbito privado, vigia como princípio a autonomia da vontade diante do reconhecimento da igualdade formal entre os indivíduos (essa disciplina jurídica incumbia o Código Civil) (SARMENTO, 2010).

Há, inclusive, quem caracterize o liberalismo como uma teoria antiestado, visto que o aspecto central é o indivíduo e suas iniciativas, cabendo à atividade estatal, quando ocorre, um espaço reduzido, previamente reconhecido (e regulamentado pela lei). Em regra, é do Estado a tarefa de manutenção da ordem e da segurança - até mesmo para que eventuais disputas sejam resolvidas de forma imparcial, sem interferência da força privada -, além de proteção das liberdades civis e pessoais, a fim de assegurar a liberdade econômica dos indivíduos no mercado capitalista (Estado Mínimo). Com efeito, o papel do Estado é negativo, pois todas as intervenções que extrapolem essas tarefas são más, por enfraquecerem a independência e a iniciativa individuais (STRECK; BOLZAN DE MORAIS, 2001).

As Constituições liberais, por sua vez, constituem um documento eminentemente jurídico, cuja prerrogativa maior é a imposição de limites ao Estado e a garantia dos direitos individuais negativos ${ }^{1}$. Apenas no segundo pós-guerra as Constituições passam a ser concebidas como "comunitárias", ou seja, reflexo dos valores compartilhados pela comunidade que as adota, dando origem à chamada Teoria Material da Constituição, a qual propõe levar em consideração os princípios políticos, a ideologia, o sentido e os fins que conformam a Constituição (LEAL, 2007).

De qualquer forma, é sabido que a igualdade formal - pressuposto da liberdade - preconizada pelo Estado Liberal através da lei não

Tratam-se dos chamados direitos de primeira dimensão, os quais, ao menos no âmbito de seu reconhecimento nas primeiras Constituições escritas, são o produto peculiar do pensamento liberal-burguês do século XVIII, de marcado cunho individualista, afirmando-se como direitos do indivíduo frente ao Estado (direitos de defesa) - daí a designação de "negativos" (SARLET, 2009). 
assegurou a igualdade material, intensificando-se as críticas a esse modelo, cuja legitimidade foi esvaziada e provocou a luta e a busca por definições materiais do Estado de Direito. Isso reflete diretamente na interpretação - bem como no próprio conteúdo e natureza/característica - dos direitos fundamentais.

Assim, se até então os direitos fundamentais se prestavam a garantir a liberdade individual frente ao Estado, a essa função será adicionada a de delimitar e controlar o Estado, bem como a de legitimar e estimular a realização de objetivos e tarefas materiais por esse mesmo Estado (BÖCKENFÖRDE, 2000).

As desigualdades materiais geradas pelo modelo liberal se encarregaram, pois, de promover a sua substituição pelo Estado Social, cujo paradigma é de garantia dos direitos sociais, entendidos como condições mínimas de existência para cada ser humano, inclusive, indispensáveis para o exercício dos direitos individuais. O Estado, então, passa a ser promotor desses direitos e a dicotomia público/privada sofre uma inversão, ficando marcada pela primazia do público (publicização do privado).

A partir dessa redefinição das fronteiras entre público e privado, os direitos fundamentais passam a incidir nas relações privadas. Se no modelo de Estado Liberal tais direitos foram confinados às relações entre indivíduo e Estado, a passagem para o Estado Social traz a compreensão de que também os indivíduos podem assumir a condição de sujeitos passivos dos direitos fundamentais, especialmente considerando-se o poder crescente de instâncias não estatais, como grandes empresas e grupos econômicos.

Diante da constatação de que a opressão e a injustiça podem ocorrer também nas relações privadas travadas no mercado, nas relações laborais, na sociedade civil, na família e em tantos outros espaços (ou seja, não provêm apenas dos poderes públicos), "nada mais lógico do que estender a estes domínios o raio de incidência dos direitos fundamentais, sob pena de frustração dos ideais morais e humanitários 
em que eles se lastreiam" (SARMENTO, 2010, p. 25). Ademais, a ficção da igualdade jurídica entre os indivíduos (igualdade meramente formal) em um contexto de gritantes desigualdades sociais legadas do Estado Liberal não mais justifica a imunidade dos particulares aos direitos fundamentais.

Reis (2007) destaca à autonomia privada o status de direito constitucional fundamental, logo, no caso de eventual colisão desse direito com os demais, a solução deve ser buscada pela ponderação Nisso, alguns critérios acabam se sobressaindo, como a máxima de que quanto maior for a igualdade entre as partes, maior será o grau da autonomia privada (sendo também válida a recíproca inversa), e, ainda, a questão da essencialidade do bem envolvido na relação jurídica (quanto mais essencial o bem, menor a proteção à autonomia). De todo modo, ele conclui que a autonomia privada, hoje, ao mesmo tempo em que pode ser limitada pelos direitos fundamentais, também pode ser causa de restrições a outros, dependendo do caso concreto. Como bem lembrado pelo autor, não há no Brasil direito fundamental absoluto.

A Constituição, assim, de meramente limitadora do poder do Estado e organizadora da formação política de vontade e de exercício do poder, converte-se em plano de ação política para esse poder e em positivação jurídica dos valores fundamentais da ordem da vida em comum (ordem objetiva de valores), à qual todos estão vinculados, inclusive, evidentemente, os particulares (LEAL, 2007).

As crises econômicas e a globalização debilitaram o Estado, enfraquecendo o poder deste de subordinar os fatores econômicos e sociais que condicionam as comunidades políticas e ditam o rumo de suas vidas. Por isso, tornam-se cada vez mais importantes, nas economias nacionais, variáveis exógenas, sobre as quais o ente estatal não exerce nenhum poder ou controle (SARMENTO, 2010).

Nesse sentido, impõe-se a referência a Dowbor (2008), que avalia a relação entre poder político (estatal) e econômico defendendo a democratização da economia, justamente por considerar o surgimento de um amplo poder político com aspecto de poder econômico (grandes 
empresas e grupos privados), o qual não poderia ser submetido ao controle político, pois seria regulado pelas forças de mercado, logo, por força nenhuma.

Nesse novo contexto (pós-social), não apenas a relação Estado/ indivíduo pode ser marcada pela verticalidade/desigualdade, mas também as relações eminentemente privadas, parecendo evidente a necessidade ainda maior da vinculação dos particulares aos direitos fundamentais (SARMENTO, 2010).

$\mathrm{Na}$ democracia capitalista globalizada, consideram-se insuficientes os instrumentos de proteção de direitos fundamentais postos à disposição do poder público se estes não puderem se estender à atividade privada, sobretudo a econômica. A Constituição tem um rol de princípios fundamentais justamente para condicionar e conformar, no plano hermenêutico, todo o tecido normativo. Assim, define-se uma nova ordem pública, agora calcada na tutela da pessoa humana (funcionalizando a atividade econômica privada aos valores existenciais e sociais insculpidos no texto constitucional) e da qual não se podem excluir as relações jurídicas privadas (TEPEDINO, 2004).

Na consagração do Estado Democrático de Direito, que sucede o Estado Social em crise, tem-se um período marcado pelo recrudescimento da noção dos direitos fundamentais, no qual a Constituição assume uma função principiológica, ampliando-se e expandindo-se para abarcar todos os conteúdos da realidade (LEAL, 2007).

De fato, "o reconhecimento da força normativa da Constituição e do caráter vinculante dos seus princípios contribuíram decisivamente para que fosse desencadeado o processo constitucionalizador do Direito Privado [...]", que relativizou a própria dicotomia público/privado. Ressalva-se, contudo, que a constitucionalização "não se resume ao acolhimento, em sede constitucional, de matérias que no passado eram versadas no Código Civil”. O fenômeno é muito mais amplo, importando uma verdadeira releitura do Código Civil, das leis especiais e de todo o ordenamento à luz da Constituição Federal (SARMENTO, 2010, p. 102). 
Como decorrência desse quadro de constitucionalização do Direito, faz-se distinção entre a chamada eficácia vertical (vinculação das entidades estatais) e eficácia horizontal dos direitos fundamentais (que compreende, em apertada síntese, a problemática da vinculação desses direitos no âmbito das relações entre particulares). Quanto a esse aspecto, algumas teorias se destacam - na tentativa de explicar como se dá a vinculação dos particulares aos direitos fundamentais diante do amplo consenso de que pelo menos algum tipo de vinculação há. Para tanto, o problema do "como" é investigado a partir de, basicamente, duas teorias: a da eficácia direta (imediata) e a da eficácia indireta (mediata) (SARLET, 2000).

Para a primeira, os direitos fundamentais não carecem de qualquer transformação para serem aplicados no âmbito das relações jurídicoprivadas, ou seja, como a própria nomeação da corrente anuncia, aplicam-se tais direitos diretamente nas relações entre particulares. Por outro lado, de acordo com a segunda teoria, os direitos fundamentais carecem de uma intermediação para vincularem os particulares, isto é, de uma transposição a ser efetuada, sobretudo pelo legislador, e na sua falta, pela jurisdição (SARLET, 2000).

Ainda quanto à teoria da eficácia direta, cumpre o registro de que, em geral, seus defensores não negam a existência de especificidades nessa incidência, tampouco a necessidade de ponderação entre o direito fundamental e a autonomia privada envolvidos no caso concreto. Com relação à teoria da eficácia indireta, destaca-se o entendimento de que "os direitos fundamentais não ingressam no cenário privado como direitos subjetivos, que possam ser invocados a partir da Constituição" (SARMENTO, 2011, p. 138-143), daí a necessidade de intermediação pelo legislador, pois a incidência de tais direitos no campo privado reclama a sua proteção por instrumentos típicos desse âmbito (e não por via constitucional).

Embora essas sejam as duas principais correntes, existem outros posicionamentos, como: (1) a teoria dos deveres de proteção (defende a imposição ao Estado de deveres de proteção dos direitos fundamentais, 
inclusive quando a ameaça provém de terceiros/particulares); (2) a vinculação dos denominados "poderes privados" (quando for verificado que tal poder é gerador de uma relação marcada pela verticalidade, semelhante a quando em um dos polos se encontra o ente estatal); (3) a teoria da "convergência estatista" (sustenta que a atuação dos particulares no exercício da autonomia privada é sempre produto de uma autorização estatal, portanto, as ofensas aos direitos fundamentais daí decorrentes são sempre responsabilidade do Estado); e (4) a teoria da state action (segundo a qual os direitos fundamentais vinculam somente ao Estado, não alcançando de forma alguma os particulares). De qualquer modo, afirma-se a superação das teorias que negam uma vinculação das entidades privadas aos direitos fundamentais, ainda que a medida dessa vinculação permaneça controversa (SARLET, 2000).

Compreendido o desenvolvimento da noção de direitos fundamentais no Estado Constitucional e firmado o entendimento da incidência deles quanto aos particulares (especialmente a partir do fenômeno constitucionalizador), bem como analisadas as principais formas (teorias) que se ocupam em explicar sua eficácia nas relações entre privados, cumpre investigar a posição da jurisdição constitucional brasileira relativamente a esses aspectos. Essa perspectiva é objetivo do item seguinte, traçada com base na análise da jurisprudência do Supremo Tribunal Federal.

\section{OSupremo Tribunal Federal e a vinculação dos particulares aos direitos fundamentais após a Constituição Federal de 1988: ativismo judicial?}

No contexto nacional, alterações na forma de atuação do Judiciário, especialmente da jurisdição constitucional, bem como reflexo dos aspectos vistos (supremacia da Constituição, recrudescimento dos direitos fundamentais etc.), começaram a ser percebidas claramente a partir do advento da Constituição Federal de 1988, que coroou o Estado Democrático de Direito no Brasil. 
Além disso, os compromissos assumidos por essa Constituição, destacadamente aqueles previstos em seus três primeiros artigos, fazem com que ela seja classificada, segundo a sua estruturação, como constituição dirigente, por não se reduzir a um mero ordenamento político, mas também contemplar aspectos que a permitam ser vista como ordenamento econômico e social (MOREIRA, 2011).

A partir dessa nova conformação, o Judiciário é tão responsável quanto os demais Poderes pela consecução dos objetivos fundamentais da República Federativa do Brasil. Sendo poder constituído, subordinado à vontade constituinte, não tem o direito de sentir-se alheio ao projeto de edificar uma sociedade livre, justa e solidária (NALINI, 2008).

Diante de um novo papel para o Direito e para a Constituição, inovam-se as perspectivas da jurisdição constitucional, cujas implicações com o desenvolvimento que conduziu a essa original conformação restam evidentes. Trata-se de um novo contexto, de uma complexa realidade, de uma diferente postura reclamada e notada em relação ao Judiciário. A própria discussão acerca da eficácia dos direitos fundamentais nas relações privadas tem como pano de fundo o estabelecimento de limites à atuação dos Poderes, notadamente no atual quadro de conformação do Estado Democrático de Direito.

Constata Cittadino (2002, p. 39) que "a própria Constituição de 1988 instituiu diversos mecanismos processuais que buscam dar eficácia aos seus princípios", sendo essa tarefa atribuída não só aos tribunais, posto que reclama também uma cidadania juridicamente participativa. A atuação dos tribunais dependerá, sobretudo, "do nível de pressão e mobilização política que, sobre eles, se fizer".

Sendo assim, impende compreender e destacar o posicionamento da jurisdição constitucional brasileira em relação às teorias que sustentam e justificam a aplicabilidade (ou não) dos direitos fundamentais nas relações privadas. Nesse sentido, não há dúvida de que, mais uma vez, a Constituição Federal de 1988 foi um marco significativo. Tanto 
que a verificação proposta pode ser divida entre antes e depois desse período?

Nos casos anteriores à Constituição de 1988, não se identifica uma posição clara do Supremo Tribunal Federal quanto à vinculação dos particulares aos direitos fundamentais. Em alguns momentos, como no julgamento do Recurso Extraordinário n. 63.279, julgado em 1968, que versava sobre a validade de cláusulas do Estatuto Social do "Santos Football Club", impugnadas por associado sob a alegação de ofensa ao princípio da igualdade, extrai-se inclinação à premissa tradicional de que a incidência dos direitos fundamentais se limita à esfera das relações ocorridas na esfera pública, com a presença do Estado. Por outro lado, alguns anos depois (Recurso Extraordinário n. 85.439, julgado em 1977), o Tribunal reconheceu a vinculação de particulares a certas emanações do direito à privacidade, inadmitindo como meio de prova de adultério em ação de desquite a gravação telefônica feita sem o conhecimento de um dos interlocutores. Destaca-se, apesar disso, que o voto condutor dessa decisão não chegou a invocar diretamente preceitos constitucionais. Essa referência expressa à vinculação dos particulares aos direitos fundamentais (especificamente quanto aos direitos de personalidade) apareceu apenas em 1984, no julgamento do Recurso Extraordinário n. 100.094, ao ser apreciada novamente a questão da gravação telefônica feita sem consentimento (SARMENTO, 2011).

Após o advento da Constituição de 1988, notam-se duas fases quanto ao posicionamento do Supremo Tribunal Federal concernente

2 Referindo-se à experiência da Corte Constitucional italiana quanto à aplicação da doutrina do Direito Civil sob o ponto de vista da constitucionalização, Perlingieri (2008) também faz uma análise divida por fases, comentando quatro momentos diferentes quanto à forma de atuação jurisdicional. Inicialmente, anota o não envolvimento dos juízes comuns na garantia dos valores constitucionais. Num segundo momento, verificam-se significativas tomadas de posições reconhecendo a unidade do ordenamento com os preceitos constitucionais no seu topo. No marco seguinte, até mesmo o juiz comum é chamado a conformar o texto legislativo às normas da Carta Magna. Na quarta fase, finalmente, assinala-se a superação da Corte em relação ao entendimento que divide o momento interpretativo das leis ordinárias com o aplicativo das normas constitucionais. A interpretação adequada é sistemática e à luz da Constituição. 
ao tema. Inicialmente, houve um reconhecimento implícito à eficácia horizontal (isto é, entre particulares) dos direitos fundamentais, sem que a teoria fosse problematizada e enfrentada abertamente. A vinculação dos particulares aos direitos fundamentais era meramente presumida pelas decisões da Corte, de modo que não havia especificações quanto à forma dessa incidência (direta ou indireta), suas características e limites. Somente a partir do julgamento do Recurso Extraordinário n. 201.819, em 2005, é que esse panorama é alterado, inaugurando a segunda fase (após 1988) da jurisprudência do Supremo Tribunal Federal. O mencionado caso envolvia a União Brasileira de Compositores, demandada por um associado excluído ao qual não foi assegurada prévia oportunidade de defesa (SARMENTO, 2011).

Apesar das divergências entre os ministros, firmou-se o entendimento de que as violações de direitos fundamentais não ocorrem somente nas relações entre o cidadão e o Estado, mas também entre pessoas físicas e jurídicas de direito privado, de modo que, igualmente nesses casos, impõe-se a proteção desses direitos. Ressaltou-se que o espaço de autonomia que a Constituição garante não está imune à incidência dos princípios constitucionais, portanto, a autonomia privada encontra limitações de ordem jurídica, não podendo ser exercida em detrimento ou com desrespeito aos direitos e garantias de terceiros ${ }^{3}$.

3 O acórdão restou assim ementado: "Eficácia dos direitos fundamentais nas relações privadas. As violações a direitos fundamentais não ocorrem somente no âmbito das relações entre o cidadão e o Estado, mas igualmente nas relações travadas entre pessoas físicas e jurídicas de direito privado. Assim, os direitos fundamentais assegurados pela Constituição vinculam diretamente não apenas os poderes públicos, estando direcionados também à proteção dos particulares em face dos poderes privados. Os princípios constitucionais como limites à autonomia privada das associações. A ordem jurídico-constitucional brasileira não conferiu a qualquer associação civil a possibilidade de agir à revelia dos princípios inscritos nas leis e, em especial, dos postulados que têm por fundamento direto o próprio texto da Constituição da República, notadamente em tema de proteção às liberdades e garantias fundamentais. O espaço de autonomia privada garantido pela Constituição às associações não está imune à incidência dos princípios constitucionais que asseguram o respeito aos direitos fundamentais de seus associados. A autonomia privada, que encontra claras limitações de ordem jurídica, não pode ser exercida em detrimento ou com desrespeito aos direitos e garantias de terceiros, especialmente aqueles positivados em sede constitucional, pois a autonomia da vontade não confere aos particulares, no domínio de sua incidência e atuação, o poder de transgredir ou de ignorar as restrições postas e definidas pela própria Constituição, cuja eficácia e força normativa também se impõem, aos particulares, no âmbito de suas relações privadas, em tema de liberdades fundamentais." (RE 201.819, Rel. p/ o ac. Min. Gilmar Mendes, julgamento em 11-10-2005, Segunda Turma, DJ de 27-10-2006. (BRASIL. STF, 2013, on-line). 
Hoje, é clara a posição da jurisdição constitucional brasileira, exercida pelo Supremo Tribunal Federal, em defesa da vinculação dos particulares aos direitos fundamentais; tanto que a Corte os vem aplicando diretamente às relações privadas. A utilização direta da Constituição para resolver litígios particulares, independentemente da existência de normas infraconstitucionais específicas, não deixa dúvidas da opção pela teoria da eficácia direta (SARMENTO, 2011).

Aliás, cumpre concordar com o referido entendimento, pois não há mais espaço, no Estado Democrático de Direito, para interpretações dissociadas da Constituição, que rege não apenas o Estado, mas toda a sociedade e cada um de seus cidadãos.

Daí se afirmar que "o Tribunal começa a migrar, silenciosamente, de uma posição de coadjuvante na produção legislativa do poder soberano [...] para um de ativo guardião da Carta Constitucional e dos direitos fundamentais da pessoa humana" (VIANNA, 1999, p. 53).

Estando a ideia de "ativismo judicial" associada a uma participação mais ampla e intensa do Judiciário na concretização dos valores e fins constitucionais - embora possa ocorrer com maior interferência no espaço de atuação dos demais Poderes (BARROSO, 2009), mas não necessariamente -, tem-se por alinhado esse (novo) aspecto de sua atuação, com a determinação de aplicação direta da Constituição também às relações privadas.

Conforme Barroso (2009, p. 5), para quem "o ativismo judicial é uma atitude, a escolha de um modo específico e proativo de interpretar a Constituição, expandindo o seu sentido e alcance", a postura ativista se manifesta por meio de diferentes condutas, com destaque para a aplicação direta da Constituição a situações não expressamente contempladas em seu texto e independentemente de manifestação do legislador ordinário.

Em todo caso, é próprio do contexto contemporâneo de cultura democrática a projeção do papel do juiz em quase todos os aspectos da vida social. Essa projeção, todavia, não tem sido derivada de 
pretensões do Judiciário. O fato de os juízes estarem ocupando lugares tradicionalmente reservados às instituições especializadas da política e de autorregulação societal, longe de significar ambições de poder por parte do Judiciário, aponta para processos mais complexos que os limites de uma abordagem como esta não permitem aprofundar (VIANNA; BURGOS; SALLES, 2007).

A partir dos pressupostos estabelecidos pela Constituição de 1988, resultantes de todo um esforço histórico de evolução marcado pelo amadurecimento e aprimoramento dos valores a servirem de base para a formação político-social pretendida, não se pode admitir que o Supremo Tribunal Federal retroceda na sua missão constitucional, seja assumindo uma postura de passividade frente às suas atribuições no Estado Democrático de Direito, seja determinando a redução do âmbito de incidência do texto constitucional.

\section{Conclusão}

A evolução do Estado Constitucional - de Liberal a Social, consolidando-se em Democrático de Direito - operou-se em relação de causa e efeito com o desenvolvimento de fatores extremamente importantes, com destaque para o recrudescimento da noção de direitos fundamentais e a consagração da supremacia da Constituição.

Ao longo dessas transformações, superou-se a visão dicotômica entre esfera pública e privada, principalmente devido ao chamado fenômeno da constitucionalização do Direito. De igual modo, notouse um poder crescente nas mãos de entes privados, ruindo a ideia de que violações aos direitos fundamentais a partir da desigualdade das relações jurídicas (verticalidade) somente seriam possíveis com a presença do Estado.

Assentados esses dados, eclodiram teorias em defesa da eficácia horizontal dos direitos fundamentais, pregando a sua incidência também aos envolvimentos eminentemente privados. Desse quadro, destacaram- 
se as teorias da eficácia direta (imediata) e indireta (mediata) dos direitos fundamentais.

A jurisdição constitucional brasileira, exercida notadamente pelo Supremo Tribunal Federal, após anos tangenciando a matéria, posicionou-se expressamente no julgamento do Recurso Extraordinário n. 201.819, em 2005, pela vinculação dos particulares aos direitos fundamentais e, a partir de então, suas decisões têm deixado clara a opção pela aplicação da teoria da eficácia direta.

Parece acertada a direção seguida pela Corte, pois, diante da necessidade de se preservar a supremacia da Constituição e de se garantirem os direitos fundamentais no Estado Democrático de Direito, afigura-se essa corrente como a mais adequada para percorrer esses fins.

Quanto ao papel desempenhado pela jurisdição constitucional nesse contexto, caracterizado pelo que se convencionou chamar de "ativismo judicial", associado a uma participação mais intensa e efetiva do Judiciário em defesa dos fins e valores constitucionais, há que se reconhecer, senão seu acerto, a sua necessidade. Uma vez definidos os papéis do Direito e da Constituição, bem como a sua forma de incidência na ordem social, é fato que se alteram as perspectivas da jurisdição constitucional, pois uma postura diferente passa a ser notada e reclamada.

\section{Referências}

BARROSO, Luís Roberto. Retrospectiva 2008: judicialização, ativismo e legitimidade democrática. Revista Eletrônica de Direito do Estado, Salvador, n. 18, abr./jun., 2009. Disponível em: <http://www. direitodoestado.com.br/rede.asp>. Acesso em: 10 jun. 2010.

BÖCKENFÖRDE, Ernst-Wolfgang. Estudios sobre el estado de derecho y la democracia. Madrid: Trotta, 2000.

BRASIL. Supremo Tribunal Federal. Recurso extraordinário n. 201.819. Relator Min. Gilmar Mendes. Julgamento em 11-10-2005. 
Disponível em: <http://www.stf.jus.br/portal/principal/principal.asp>. Acesso em: 7 dez. 2011.

CITTADINO, Gisele. Judicialização da política, constitucionalismo democrático e separação de poderes. In: VIANNA, Luiz Werneck (Org.). A democracia e os três poderes no Brasil. Belo Horizonte: Ed. UFMG; Rio de Janeiro: IUPERJ/FAPERJ, 2002.

DOWBOR, Ladislau. Democracia econômica: alternativas de gestão social. Petrópolis: Vozes, 2008.

LEAL, Mônia Clarissa Hennig. Jurisdição constitucional aberta: reflexões sobre a legitimidade e os limites da jurisdição constitucional na ordem democrática: uma abordagem a partir das teorias constitucionais alemã e norte-americana. Rio de Janeiro: Lumen Júris, 2007.

MOREIRA, Nelson Camatta. Dignidade humana na Constituição dirigente de 1988. Revista Eletrônica sobre a Reforma do Estado. Salvador, n. 12, 2008. Disponível em: <http://www.direitodoestado.com. br/rere/edicao/12/>. Acesso em: 30 out. 2011.

NALINI, José Renato. A rebelião da toga. 2. ed. Campinas, SP: Millennium, 2008.

PERLINGIERI, Pietro. A doutrina do direito civil na legalidade constitucional. In: TEPEDINO, Gustavo (Org.). Direito civil contemporâneo: novos problemas à luz da legalidade constitucional. São Paulo: Atlas, 2008. p. 1-11.

REIS, Jorge Renato dos. Os direitos fundamentais de tutela da pessoa humana nas relações entre particulares. In: REIS, Jorge Renato dos; LEAL, Rogério Gesta (Org.). Direitos sociais e políticas públicas: desafios contemporâneos. Santa Cruz do Sul: Edunisc, 2007. p. 20332064.

SARLET, Ingo Wolfgang. Direitos fundamentais e direito privado: algumas considerações em torno da vinculação dos particulares aos direitos fundamentais. In: SARLET, Ingo Wolfgang (Org.). A Constituição concretizada: construindo pontes com o público e o privado. Porto Alegre: Livraria do Advogado 2000. p. 113-114. 
A eficácia dos direitos fundamentais: uma teoria geral dos direitos fundamentais na perspectiva constitucional. 10. ed. Porto Alegre: Livraria do Advogado, 2009.

SARMENTO, Daniel. Direitos fundamentais e relações privadas. 2. ed. Rio de Janeiro: Lumem Juris, 2010.

A vinculação dos particulares aos direitos fundamentais: o debate teórico e a jurisprudência do STF. In: SARMENTO, Daniel; SARLET, Ingo Wolfgang. (Coords.). Direitos fundamentais no Supremo Tribunal Federal: balanço e crítica. Rio de Janeiro: Lumen Juris, 2011. p. 131-171.

STRECK, Lenio Luiz; BOLZAN DE MORAIS, José Luis. Ciência política e teoria geral do Estado. 2. ed. rev. e ampl. Porto Alegre: Livraria do Advogado, 2001.

TEPEDINO, Gustavo. Temas de direito civil. 3. ed. atual. Rio de Janeiro: Renovar, 2004.

VIANNA, Luiz Werneck et al. A judicialização da política e das relações sociais no Brasil. Rio de Janeiro: Revan, 1999.

VIANNA, L. J. W. ; BURGOS, C. M. M. B.; SALLES, P. Dezessete anos de judicialização política. Tempo Social, v. 19, p. 39-85, 2007.

Recebido em: 10/12/12

Aprovado em: 10/12/13 